\title{
Modeling the Smart Factory Manufacturing Products Characteristics: The Perspective of Energy Consumption
}

\author{
A.B.M. Salman Rahman, Myeongbae Lee, Jonghyun Lim, Yongyun Cho, \\ and Changsun Shin \\ Department of Information \& Communication Engineering, Sunchon National University, Suncheon 57922, Republic of Korea \\ Correspondence should be addressed to Changsun Shin; csshin@scnu.ac.kr
}

Received 5 November 2021; Revised 25 November 2021; Accepted 11 December 2021; Published 31 December 2021

Academic Editor: Daqing Gong

Copyright (c) 2021 A.B.M. Salman Rahman et al. This is an open access article distributed under the Creative Commons Attribution License, which permits unrestricted use, distribution, and reproduction in any medium, provided the original work is properly cited.

\begin{abstract}
Economic progress is built on the foundation of energy. In the industrial sector, smart factory energy consumption analysis and forecasts are crucial for improving energy consumption rates and also for creating profits. The importance of energy analysis and forecasting in an industrial environment is increasing speedily. It is a great chance to provide a technical boost to smart factories looking to reduce energy usage and produce more profit through the control and optimization modeling. It is tough to analyze energy usage and make accurate estimations of industrial energy consumption. Consequently, this study examines monthly energy consumption to identify the discrepancy between energy usages and energy needs. It depicts the link between energy consumption, demand, and various industrial goods by pattern recognition. The correlation technique is utilized in this study to figure out the link between energy usage and the weight of various materials used in product manufacturing. Next, we use the moving average approach to calculate the monthly and weekly moving averages of energy usages. The use of data-mining techniques to estimate energy consumption rates based on production is increasingly prevalent. This study uses the autoregressive integrated moving average (ARIMA) and seasonal autoregressive integrated moving average (SARIMA) to compare the actual data with forecasting data curves to enhance energy utilization. The Root Mean Square Error (RMSE) performance evaluation result for ARIMA and SARIMA is 8.70 and 10.90, respectively. Eventually, the Variable Important technique determines the smart factory's most essential product to enhance the energy utilization rate and obtain profitable items for the smart factory.
\end{abstract}

\section{Introduction}

Electricity is now the strongest adaptable energy source and one of the most important infrastructure inputs for economic development. In the present world, so much energy is used for both economic and population expansion. So, we have to think about ways to reduce our energy consumption. Due to rapid economic expansion, global electric power consumption and other energy consumption have increased. In the meantime, electricity is a need in our everyday activities and one of the essential drivers of economic progress $[1,2]$. Electricity is used by industrial customers' facilities and equipment to process, produce, or assemble commodities in industries as diverse as producing, mining, farming, and construction. The industrial sector consumes over a third of the country's electricity power. Consequently, predicting electrical energy consumption for a country or region has become crucial [3]. In smart factories, energy modeling and analysis have become a time-consuming procedure. Industrial energy consumption predictions can make a better decision to reasonably control all kinds of equipment for reducing energy consumption and make good things for industrial factories. Industrial firms recognize the need to monitor and forecast energy consumption data in conjunction with production data for profit. For improving the energy utilization of a factory, this is the best time to work as a supportive technological hand with industrial plants.

The industrial division is one of the essential divisions that require vitality steadiness. Since about the early 1990s, 
South Korea's fabricating industry has proceeded to create at high speed and has ended up the most driving drive of the proceeded quick improvement of South Korea's economy. During the 1990s, essential vitality use increased at a yearly rate of 7.5 percent, which was greater than the 6.5 percent annualized rate of financial growth during the same era. It was inferable to the sharp development of energy-intensive businesses, which incorporates the petrochemical industry. The sharp rise in power utilization for mechanical use extended the vitality transformation misfortune, which advance undermined vitality escalated. The growth of energy enterprises after 2009 helped the country weather the global financial crisis, but it had the opposite effect on the country's overall energy proficiency $[4,5]$. Numerous ambiguous elements, such as industry framework, innovation degree, energy cost, financial scale, and national arrangement, impact how firms use energy.

The accomplishments of the third development of science and technology have made the life more approachable. Industrial production seems to be a crucial component of the economy and a massive economic indicator for both the government and the nation. It has already campaigned for technological innovations and structural change in manufacturing sectors. The third scientific and technological revolution's productive triumphs have brightened people's lives and encouraged technical development institutes and institutions in traditional regions. Production and manufacturing industry reflects a country's or nation's financial strength. Many high-tech industrialized nations have advanced sectors as well. Despite this, they keep looking for new possibilities and restructure existing industries to maintain their unstoppability in the face of modernity and technological advancement. Germany is an excellent demonstration since the "Industry 4.0" initiative emphasizes smart growth, focusing on product quality, resource utilization, and energy consumption [6].

A smart factory is an Internet of Things concept in which a manufacturing operation is viewed as a completely advanced automated system of technology that enables facilities, technology, and transportation chains to operate without the need for human interaction [7]. All of these instances occurred in a smart factory as a result of data flow among all components of the industrial automation chain, not just the manufacturing plant and machines. The following elements make machine learning more achievable, permitting processes to operate better efficiently and save costs than if people were monitoring industrial processes. The smart factory idea relies on data gathering and analysis to unlock the potential hidden in infrastructure, people, and resources. Without the aid of a human supervisor, data may reach a suitable area in the production chain at the appropriate time in the smart factory. Data from various industrial circumstances must be gathered, evaluated, and combined to provide meaningful insights and enhance efficiency. The Internet of Things (IoT) and linked smart sensing devices are used in smart factories to make manufacturing actionable data-driven and data-enabled.

Many studies have shown that further developing energy productivity is vital for financial development [8-10].
Nasreen and Anwar have inspected the relationship between financial improvement, exchange, and assets in Asia. They found that economic development and exchange straightforwardness positively impacted vitality utilization [11]. Mechanical plant owners are also beginning to recognize that separating and deciding vitality data from generating data is extremely important for the success of their businesses or facilities. Overconsumption, weak frameworks, and squandered vitality are all factors that contribute to this problem. Due to the consequence of the rising demand, energy is regarded as one of the most vital and valuable assets. To further develop a modern processing plant's energy usage, it is about to work with the leading administration group of mechanical industrial facilities as a solid improvement $[10,12]$.

This study has two types of data sets: industrial energy consumption data set and industrial manufacturing data set or productions data set. This study deals with analyzing usages of energy consumption for every month with every hour data to find out the difference or relation between usages of energy consumption and demands of energy consumptions. Make a relation curve among usages of energy and energy demands, with different materials weight for manufacturing product. This study used the correlation technique to identify the significant association between energy and the importance of other materials used in producing things. Also, find out monthly and weekly moving averages for different types of materials, usages of energy, and energy demands. We use the ARIMA and seasonal AIMA to compare actual data with anticipated data curves to increase the energy consumption rate. Finally, the variable importance approach is used to determine the most significant product for the smart factory in order to enhance the energy utilization rate for industrial factory profit.

\section{Related Works}

Several scholars have studied the topic of estimating energy demand using data-mining techniques for a long time. A number of statistical and Artificial Intelligence (AI) algorithms have been developed to estimate energy consumption patterns. Machine learning techniques are beneficial and convenient for a normal operator to utilize after constructing the model; they are becoming increasingly widespread in a number of applications $[12,13]$.

The IoT idea anticipates a constant rise in the number of devices, which creates the challenge of categorizing them for various reasons. The system classes have been established so far focused on their semantic qualities, meaning, performance, or usage domain. As the Internet of Things has risen in popularity, numerous professional standards bodies, corporations, and associations in IK technologies and academia have defined the notion $[14,15]$.

National governments need to anticipate the use of force in setting energy policies and adjusting industrial structures. Consequently, it goes without saying that a strong prediction strategy is essential for the study of energy systems. Energy consumption is historically difficult due to the limited sample size, nonlinearity, and unpredictability of yearly 
energy consumption sequences. It carries high levels of uncertainty of supply and use [16-18]. The Nonlinear Grey Bernoulli Model (NGBM) is a one-of-a-kind grey forecasting model that has already been utilized to solve the challenge of predicting energy consumption in nonlinear small sample data. Pao and colleagues devised an iterative numerical approach to enhance the $\operatorname{NGBM}(1,1)$ and used it to anticipate Russia's consumption of renewable, nuclear, and total energy $[19,20]$.

Predicting energy consumption has long been considered a critical and challenging problem in industry and academics. Accurate energy consumption forecasting may aid in the allocation of energy resources, the formulation of energy-saving strategies, and the improvement of the energy system. Meanwhile, precise energy forecasting may assist managers in adopting market research management and accelerating economic growth. Its breakthroughs may theoretically be used to anticipate a wide range of time series, including traffic flow, weather, temperature, stock price prediction, and solar radiation prediction [21, 22].

Building Management Modeling is promoted chiefly and used in the cost management of civil and public structures, but it is rarely used in the power construction industry [12]. Electric power construction projects encompass a wide range of professions as well as many types of buildings and structures. Significant bottlenecks arose when these qualities were paired with Chinese laws on particular quantity computation. When these variables were paired with Chinese certain quantity computation norms, BIM implementation presented specific issues $[23,24]$.

The prosperity of the global economy is dependent on production. On the other hand, environmental resources have been rapidly destroyed in current history, culminating in a host of ecological and societal challenges, owing in significant part to the industry's expansion. According to trustworthy data, the industry consumes more energy than other sectors, accounting for more than 37 percentage points of total world energy provided. In the industrial sector, manufacturing necessitates substantial energy [12, 25].

The energy-saving and emission-reduction (ESER) plan are critical in ensuring the industrial industry's long-term viability in the green transition. This research looks at current ESER methodologies and their limitations in the manufacturing business. It introduces the lean energysaving and emission-reduction (LESER) idea and a strategy for increasing energy efficiency and lowering waste emissions. The following phases are used to build a technique for executing the LESER strategy: (i) explanation of the existing condition; (ii) investigation of the underlying cause; (iii) development; (iv) greenhouse gas evaluation; (v) maintaining and standardizing [26]. Hsiao Tien Pao has released a study using state-space modeling to anticipate Taiwan's power consumption and economic growth. SARIMA models are as good as STSP or ECSTSP models for shortterm predictions. ECSTSP is the best model for long-term projection because it considers the counteraction relationship between real GDP and EL [27].
In the manufacturing industry, smart manufacturing and data analytics may help since the current situation transmission, and data analysis from across the plant gives manufacturing intelligence that may favorably affect all parts of operations. The predictive analysis aids smart manufacturing in a variety of ways. In this work, the authors aimed to extract values from a smart manufacturing organization using predictive analysis to derive energy use based on previous data [28]. Figure 1 depicts the components of a smart factory. Smart factories are powered by the Industrial Internet of Things (IIoT), which connects smart devices and sensors to the factory to make industrial activities datadriven and data-enabled. We can easily discover the smart factory content with the smart security system, sensor technologies, application software, smart management, processing facilities, data analytics solutions, and organizational efficiency. The Industrial Internet of Things (IIoT) is a full bundle in a smart factory (IIoT).

\section{Methodology}

3.1. Correlation. Use Measurement of linear connection between two quantitative variables is commonly referred to as correlation. If there is no identifiable response variable, correlation is typically employed. It assesses the quality (quantitatively) and direction of a linear relationship between two or more variables [29]. A correlational investigation can provide three outcomes: a positive correlation, a negative correlation, and no correlation. A two-variable association with a positive correlation is one in which both parameters move in similar directions. As a result, when one variable rises the other falls, or when one variable falls the other falls. Height and weight are an example of a positive association. Taller folks are often heavier. A negative correlation is a link among two variables in which an increase in one variable causes the other to drop. Height above sea level and temperature is an example of a negative association. It gets colder as we climb the mountain (ascend in elevation) (decrease in temperature). When there is no connection between two variables, a zero correlation is called. For example, there is no link between the amount of tea consumed and cognitive level. The most widely used correlation measurement is Pearson's product-moment correlation, which is generally applied as the correlation or the correlation coefficient. The Pearson correlation coefficient measures the linear connection between $X$ and $Y$ variables, often known as bivariate correlation. It has a range of values from +1 to -1 , with +1 denoting total positive linear correlation, -1 denoting actual negative linear correlation, and 0 denoting no linear correlation.

The characteristic features of the correlation are provided in the following:

(i) A complete positive correlation is characterized by a correlation of 1

(ii) A complete negative correlation is characterized by a correlation of 1 


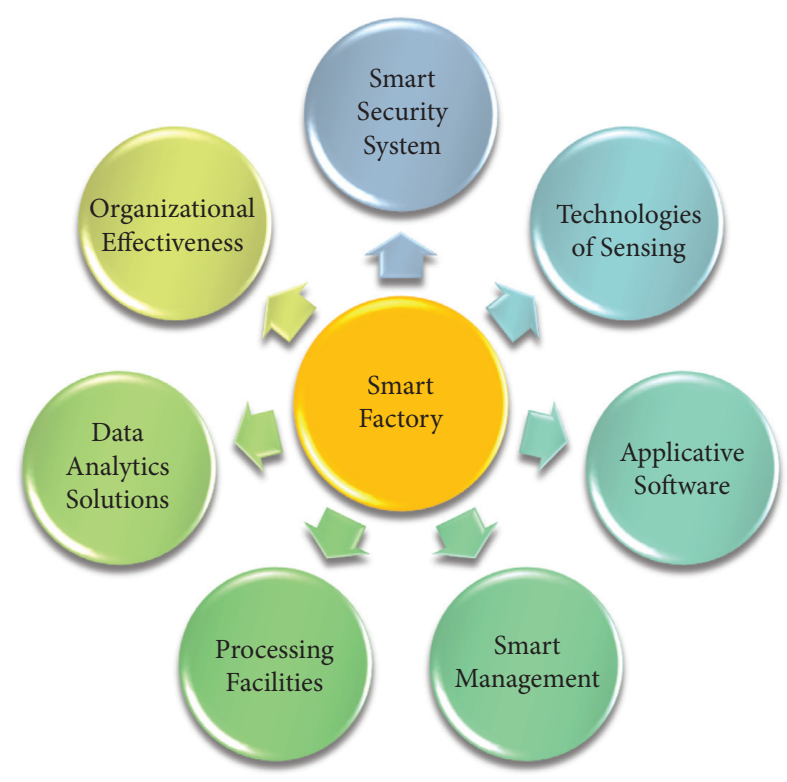

Figure 1: Components of the smart factory.

(iii) A correlation of 0 means that the variables have no connection

(iv) Values between -1 and 1 represent the strength of the relationship

We assumed a model:

$$
r=\frac{\sum\left(x-m_{x}\right)\left(y-m_{y}\right)}{\sqrt{\sum\left(x-m_{x}\right)^{2} \sum\left(y-m_{y}\right)^{2}}} .
$$

The mean value of the $x$ and $y$ variables are $m$ and $y$, respectively.

3.2. Moving Average. A moving average (MA) is a wide marker in specialized examination that makes a difference in a smooth-out cost activity by sifting out the commotion from irregular short-term cost determinations. It is a trendfollowing or lagging indicator based on the past. The two fundamental and commonly utilized moving midpoints are the simple moving normal (SMA), the basic normal of a security over a characterized number of periods, and the exponential moving average (EMA), which typically gives more significant weight to more later costs [30]. The foremost typical applications of moving average are recognizing the slant heading and deciding back and resistance levels.

We assumed a model:

$$
\mathrm{SMA}=\frac{A_{1}+A_{2}+\cdots+A_{n}}{n} .
$$

The simple moving average calculates the arithmetic mean over a number of $n$ periods, $A$.

3.3. Time Series Forecasting. The time series is a collection of very sound data points that are obtained at regular intervals across time. By fitting appropriate models to time series data points, time series analysis helps us understand the underlying processes that contribute to a specific pattern in the data points and forecast and monitor the data points [31]. This study uses two types of time series forecasting models: ARIMA and seasonal ARIMA (SARIMA).

3.4. ARIMA Forecasting. Attach ARIMA models are a wellknown and adaptable course of determining models that utilize chronicled data to create the forecast. The autoregressive integrated moving average, or ARIMA, is defined by three order parameters $(p, d$, and $q)$. The method of fitting an ARIMA is demonstrated now and then alluded to as the Box-Jenkins strategy $[32,33]$. An autoregressive component relates to past values in the regression equation for series $Y$. The autoregressive parameter $p$ specifies the number of lags used in the model.

Assume the model equation for ARIMA:

$$
y_{t}=c+\phi_{1} y_{t-1}+\cdots+\phi_{p} y_{t-p}+\theta_{1} e_{t-1}+\cdots+\theta_{q} e_{t-q}+e_{t} \text {. }
$$

Here, $y_{t}$ is the variable described at time $t, \mathrm{c}$ is the constants or intercept, $\phi$ is the coefficient of each parameter $p, \theta$ is the coefficient of each parameter $q$, and $e_{t}$ is the residuals or errors in time $t$.

3.5. Seasonal ARIMA Forecasting. A seasonal structure can also be used to specify an ARIMA model. It is called seasonal ARIMA (SARIMA). This example defines the model by two sets of order parameters $(p, d, q)$ as order parameters and $(P, D, Q)_{m}$ parameters that describe the seasonal pattern of $m$ intervals [34, 35].

For SARIMA, the assumed model equation $(p, d, q)$ $(P, D, Q)[s]$ is

$$
\Phi_{p}\left(B^{s}\right) \phi_{p}(B) \nabla_{s}^{D} \nabla^{d} Z_{t}=\theta_{q}(B) \Phi_{Q}\left(B^{s}\right) a_{t} .
$$

Here,

(i) $\Phi_{p}\left(B^{s}\right)=\left(1-\Phi_{1} B^{s}-\ldots-\Phi_{p} B^{s P}\right)$ is the seasonal autoregressive operator of order $\mathrm{P}$

(ii) $\phi_{p}=\left(1-\phi_{1} B-\cdots-\phi_{1} B^{p}\right)$ is the autoregressive operator of order $\mathrm{P}$

(iii) $\nabla_{s}^{D}=\left(1-B^{s}\right)^{D}$ represents the seasonal differences and $\nabla^{d}=(1-B)^{d}$ is the regular difference

(iv) $\Phi_{Q}\left(B^{s}\right)=\left(1+\Theta B^{s}+\cdots+\Theta_{Q} B^{s Q}\right)$ is the seasonal moving average of order $Q$

(v) $\theta_{q}(B)=\left(1+\theta_{1} B+\cdots+\theta_{q} B^{q}\right)$ is the regular moving average operator of order $\mathrm{Q}$

(vi) $a_{t}$ is a white noise process

3.6. Recorded Data Description. In this study, two types of data sets are available from Daewoo Steel Factory, South Korea. One of these data sets is for smart factory energy consumption data, while the other is for manufacturing or production data. From energy data sets, we get twenty-four hours' usages of energy, demands of energy, lagging reactive 
power of the current, leading reactive power of the current, percentage of leading power, and the percentage of lagging powers available. From productions data, we get details about manufacturing like date of manufacturing product, product name, materials length, materials weight, product item, and lots of information. From manufacturing, there are three types of products manufactured in that steel factory, and the products are "Sheet," "Skelp," and "Cyong."

As shown in Figure 2(a), the smart meter is associated with the electrical energy meter for the Daewoo steel industry. The smart meter computes the power values for the energy consumed and sends to the smart website where the energy consumption data is stored (https://pccs.kepco.go. $\mathrm{kr}$ ). Figure 2(b) represents the manufacturing or production sector of the Daewoo steel industry.

Table 1 presents different types of load and their timings concerning each month. The table information is collected from KEPCO (Markets, Technologies, and Strategies for the Smart Grid in Asia, 2012-2016). Based on two data sets, we analyze the total energy consumption of the year 2017, then analyze per-month energy consumption for the year 2017, and make a comparison graph between usages of energy and demands of energy in the year 2017. Figure 3 depicts the suggested design's overall flow.

The general flow of the recommended architecture is seen in Figure 3. Energy usage for manufacturing items and other energy consumption are documented using IoT-based smart meters in smart factory flowcharts. Furthermore, the structural and data modeling phases of data on energy usage are near completion. In the structured and data modeling phases, preprocessed data is employed, and energy data is captured and saved in the cloud system following this step. The same cloud-based solution is used to gather and store production data. Big data analytics techniques are utilized to estimate demand, and they are also employed for effective energy policy and product management.

Analysis usages of energy data with different material weight make a comparison graph of total usages of energy and total demands of energy with corresponding total materials weight. The industry's energy (kWh) data every 1 hour is the focus of this analysis. The one-hour reporting interval has intended to capture major energy use changes. All the data analysis is carried out in $R$ [36]. The timespan of data is 365 days (12 months). The correlations function determines the connection between total electrical energy consumption and the material weight of three different types of manufacturing goods. We use the moving average method to find weekly and monthly moving averages for manufacturing products materials and usage of energy consumption and demands. Finally, we use ARIMA and seasonal ARIMA to forecast the energy consumption and then compare the graph between actual and forecasted data for ARIMA and SARIMA. Figure 4 illustrates the period's energy consumption profile. Figure 4 illustrates the energy consumption pattern for the whole period, and we can see from the graph that the pattern is quite variable. Figure 4(a) depicts the steel industry's energy consumption in 2017, whereas Figure 4(b) depicts the steel industry's energy consumption during the first week. Figure 4(b) shows that, every day for a fixed time, energy consumption is getting high peak and after a sudden or fixed period energy consumption again gets low. After analyzing Figure 4(b), we can easily say that when the uses of energy start to rise, actual working hours start for the Daewoo Steel Factory that time and then when again uses of energy are low that time working hours are finished. Daewoo Steel Factory working hours starting and finishing times are almost the same for every day.

Figures 5 and 6 use a histogram and a boxplot to show the details of the steel factory's energy use in 2017. The data distribution displays a lengthy tail. The black line in the boxplot shows the median location, while the histogram plot depicts the current level of energy usage. Only circles considerably above the upper feathers are used to identify outliers. The median in the boxplot is depicted by a thick black line inside the grey rectangle and has a value of $2700 \mathrm{kWh}$. The bottom whisker is $10 \mathrm{kWh}$, whereas the top whisker is $3500 \mathrm{kWh}$. The outliers are branded with circles over the upper whisker. Temperature and other environmental conditions have no effect on energy usage in the steel sector since it is in an open area with no temperature control system.

3.7. Evaluation Indices. Assessing criteria are used to compute the execution of expectation models. The Root Mean Squared Error (RMSE) is used to compute the prediction's square error compared to genuine values in order to obtain the square mistake relative to actual values and, as a result, the root of the summation [37]. RMSE can also be a level-dependent parameter made up of comparable measuring unit values.

We have the following equation:

$$
\text { RMSE }=\sqrt{\frac{\sum_{i=1}^{n}\left(Y_{i}-\widehat{Y}_{i}\right)^{2}}{n} .}
$$

The Mean Absolute Error (MAE) measures how accurate a forecast is. It is a scale-dependent metric that accurately captures prediction error by eliminating the offset of negative and positive errors.

Using the equation below, we can determine MAE

$$
\mathrm{MAE}=\frac{\sum_{i=1}^{n}\left[Y_{i}-\widehat{Y}_{i}\right]}{n} .
$$

Here, $Y_{i}$ is the actual value of the computation, $\widehat{Y}_{j}$, is the expected value, and $z$ is the number of successful $Y, i$ is the actual value of the computation, $Y(j)$ is the predicted value, and $z$ is the number of successful observations.

A margin of error (ME) tells you how many percentages points your results will differ from the important population value. A 95 percent significance level with the 4 percent margin of error, for example, suggests your statistic will be within four percentage points of the key population number $95 \%$ of the time. In more technical terms, the margin of error is the measure of values below and above the sample statistic during a confidence interval. The arrogance interval may be showing what the uncertainty is with a particular statistic. 


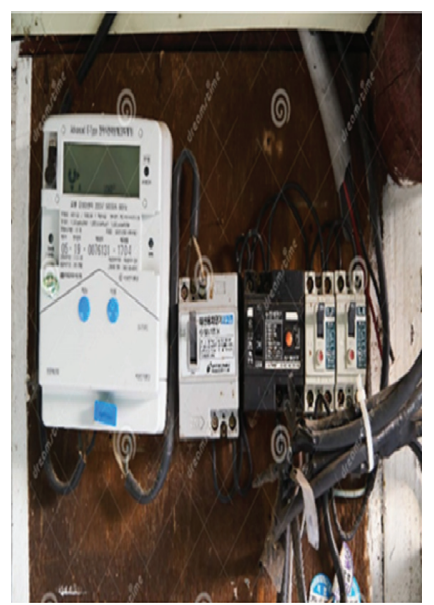

(a)

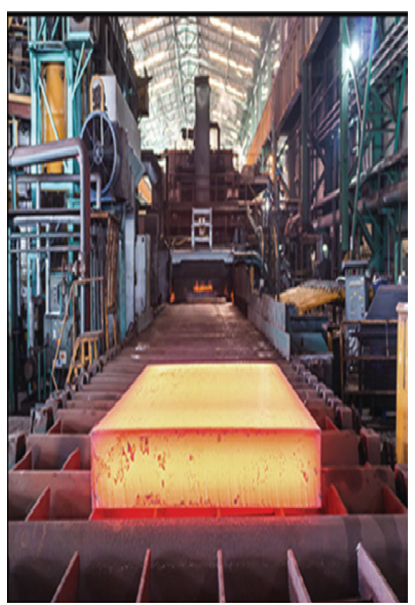

(b)

FIgURE 2: (a) Smart meter. (b) Steel industry manufacturing sector.

TABle 1: Different types of load and their timings concerning.

\begin{tabular}{|c|c|c|c|c|c|c|}
\hline \multirow[b]{2}{*}{ Categories } & & \multirow[b]{2}{*}{$\begin{array}{l}\text { Charge on demand } \\
\quad(\text { won } / \mathrm{kW})\end{array}$} & \multicolumn{4}{|c|}{ The cost of energy is expressed in won per kilowatt-hour } \\
\hline & & & $\begin{array}{l}\text { Period of } \\
\text { time }\end{array}$ & $\begin{array}{c}\text { Summer } \\
\text { (Jul 1 Aug } \\
31 \text { ) }\end{array}$ & $\begin{array}{c}\text { Spring/fall (Mar 1 Jun 30/Sep } \\
\text { 1 Oct 31) }\end{array}$ & $\begin{array}{c}\text { Winter (Nov } 1 \sim \mathrm{Feb} \\
28)\end{array}$ \\
\hline \multirow{6}{*}{$\begin{array}{l}\text { High voltage } \\
\text { (A) }\end{array}$} & \multirow{3}{*}{ Option I } & \multirow{3}{*}{5710} & $\begin{array}{c}\text { Off-peak } \\
\text { load }\end{array}$ & 45.80 & 45.80 & 49.30 \\
\hline & & & Mid-load & 87.30 & 59.30 & 85.90 \\
\hline & & & Peak-load & 147.00 & 77.60 & 120.70 \\
\hline & \multirow{3}{*}{$\begin{array}{l}\text { Option } \\
\text { II }\end{array}$} & \multirow{3}{*}{6540} & $\begin{array}{l}\text { Off-peak } \\
\text { load }\end{array}$ & 41.60 & 41.60 & 45.20 \\
\hline & & & Mid-load & 83.20 & 55.20 & 81.70 \\
\hline & & & Peak-load & 142.90 & 73.50 & 116.60 \\
\hline \multirow{6}{*}{$\begin{array}{l}\text { High voltage } \\
\text { (B) }\end{array}$} & \multirow{3}{*}{ Option I } & \multirow{3}{*}{5710} & $\begin{array}{l}\text { Off-peak } \\
\text { load }\end{array}$ & 44.40 & 44.40 & 47.90 \\
\hline & & & Mid-load & 84.80 & 57.70 & 83.30 \\
\hline & & & Peak-load & 141.80 & 75.40 & 116.70 \\
\hline & \multirow{3}{*}{$\begin{array}{l}\text { Option } \\
\text { II }\end{array}$} & \multirow{3}{*}{6540} & $\begin{array}{l}\text { Off-peak } \\
\text { load }\end{array}$ & 40.20 & 40.20 & 43.70 \\
\hline & & & Mid-load & 80.60 & 53.50 & 79.10 \\
\hline & & & Peak-load & 137.70 & 71.30 & 112.60 \\
\hline
\end{tabular}

3.8. The Equations.

$$
\mathrm{ME}=p^{*} \sqrt{\frac{\hat{j}(1-\widehat{j})}{n} .}
$$
score.

Here, $\widehat{j}$ is sample proportions, $n$ is sample size, and $z$ is $z$ -

\section{Results and Discussion}

In this sector, we analyze data to find out twenty-four hours of energy usage and energy demands and find out relations between different materials weight with uses and energy demand. We make a correlation among usages of energy and manufacturing products material weight. We find out monthly and weekly moving averages for manufacturing products and the moving average of usages and demand of energy consumption. Finally, we forecast the uses of energy and compare actual data and forecasted data to make a decision for improving energy utilization.

4.1. Analyzing Per-Day Energy Data. To check the per-hour usages of energy consumption for every day, we analyze 2017 energy consumption data. We analyze every hour energy consumption data of the year 2017 to identify each hour's energy consumption and determine the period of the high amount of energy consumption and determine the time 


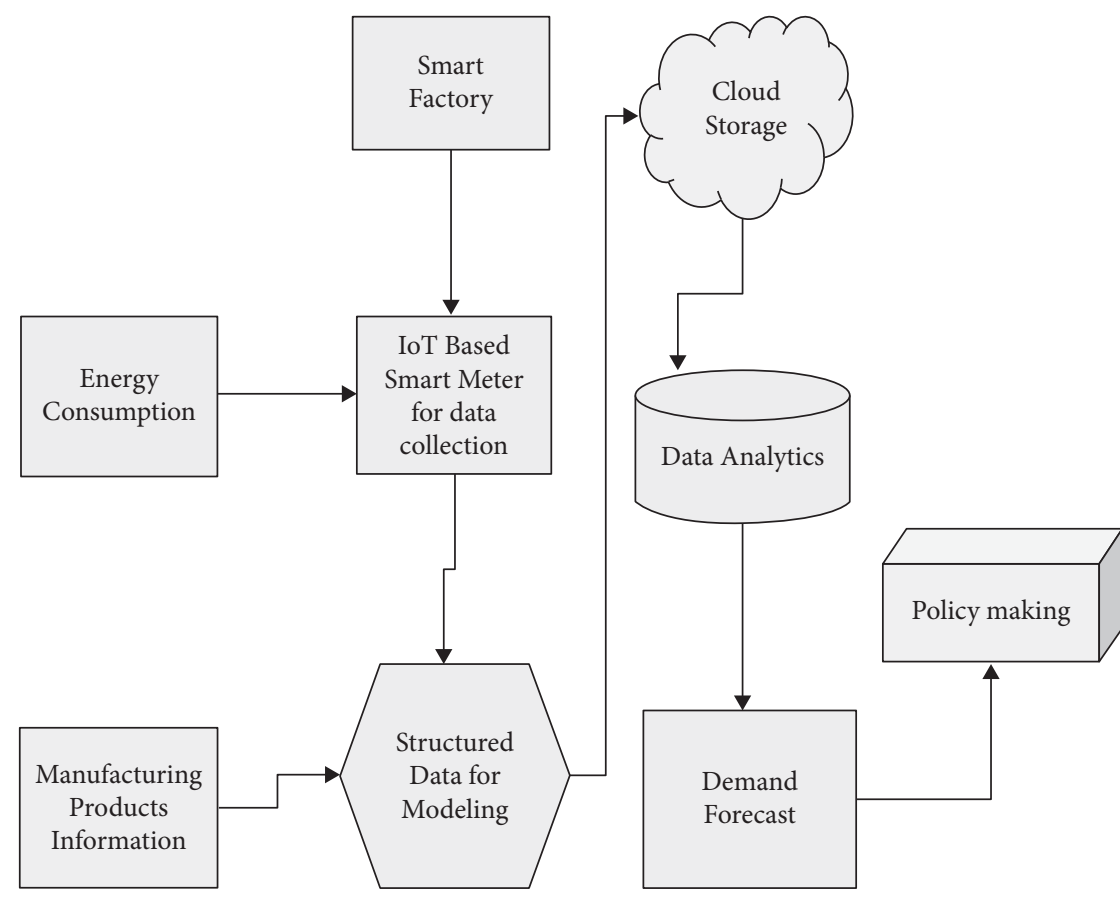

FIgURE 3: Overall flowchart of the recommended system.

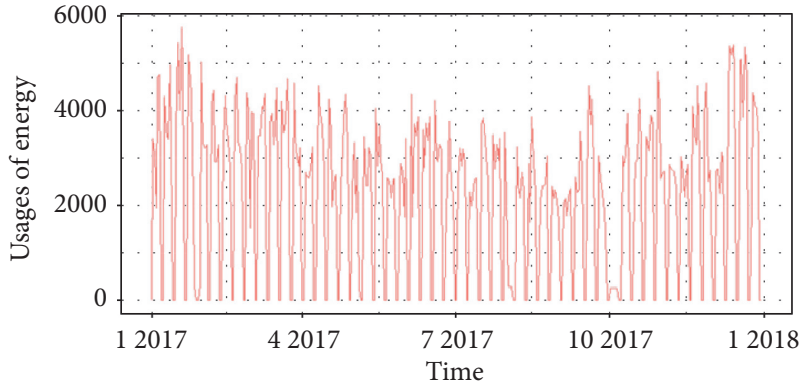

(a)

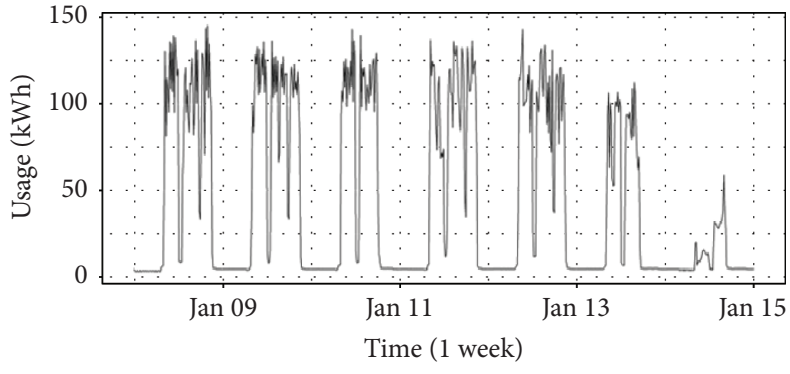

(b)

FIGURE 4: (a) Industry energy consumption measurement for the whole period. (b) Industry energy consumption for the first week.

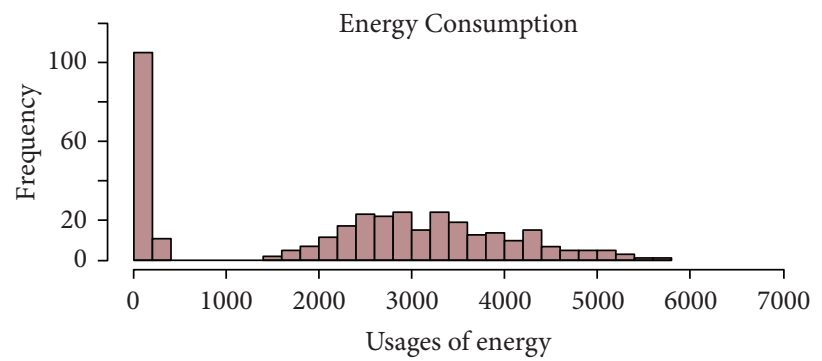

Figure 5: A histogram illustrating appliance energy usage allocation. The graph depicts the interval's frequency (bar width) of energy use.

period for less amount of usages energy. Figure 7 shows the twenty-four hours of energy consumption for each day in 2017. The $x$-axis represents time duration, while the $y$-axis represents total energy use in kWh in 2017 in the graph. We can see from the graph that energy consumption is high most days from 8 a.m. to 10 p.m., and on some days, it continues until 11 p.m., and that energy consumption is low from 11 p.m. to 8 a.m. On the basis of the diagram, we can clearly conclude that steel mill working hours begin at 8 a.m. and end at 11 p.m. 


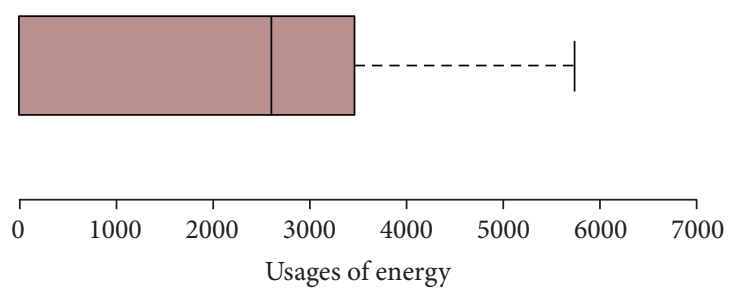

Figure 6: Distribution of appliance energy consumption. The black line in the figure shows where the median is placed.

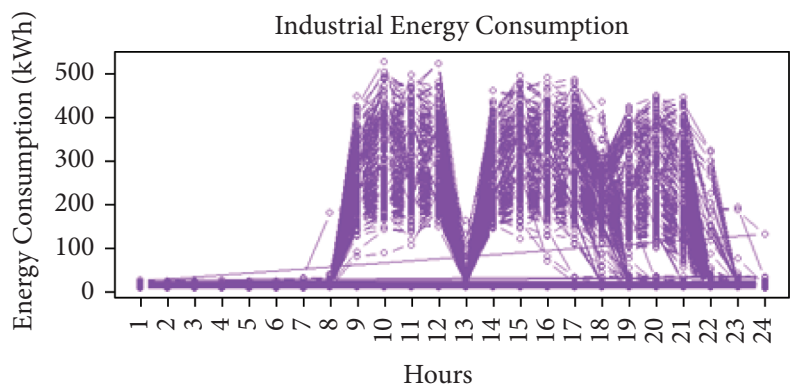

Figure 7: Energy consumption of the Daewoo Steel Factory for the year 2017.

4.2. Analyzing Per-Month Energy Data. To determine the per-hour usages of energy consumption for twelve months, we analyzed 2017 energy consumption data. We analyze total energy consumption per hour for every month from energy consumption data of the year 2017 to determine each hour's energy consumption and the time period of the high amount of energy consumption usages and the time period of less amount of usages energy.

Figure 8 shows the twenty-four hours' usages of energy of working days consumption for every month in 2017. The $x$-axis represents time duration, while the $y$-axis represents total energy use in $\mathrm{kWh}$ in 2017 in the graph. We can see from the graph that energy usage is quite high from 8 a.m. to 10 p.m. every month and that energy consumption is very low from 11 p.m. to 8 a.m. From the figure, we can simply deduce that the Daewoo Steel Factory working hours begin at 8 a.m. and end at 10 p.m.

4.3. Analyzing Energy Data with Materials Weight of Manufacturing Products. As we mentioned before, three types of products are manufactured in Daewoo Steel Factory. Here we analyze different types of materials weight of manufacturing products with total usages of energy for the number of working days. Figure 9 depicts the various types of material weights used in produced items as well as per-day total energy usages for the number of working days. In 2017, the $x$-axis represented the number of working days, while the $y$-axis represented material weight in kilograms. The blue line depicts daily energy use for working days, while the red dots depict daily material weight for sheet productions, the green dots depict daily material weight for Skelp products, and the purple line depicts daily material weight for Cyong productions. From the figure, we can say that energy consumption also increases when the density of materials increases. It means when productions are high, usages of energy consumption is also high.

Figure 10 shows the everyday total material weight of manufactured products with total usages and demands of energy consumptions for the number of working days. In 2017, the $x$-axis represented the number of working days, while the $y$-axis represented material weight in kilograms. According to the graph, the blue line represents energy use for the number of working days, the red line represents maximum energy demand, and the green line represents total weight of materials for the number of working days. From the figure, we can see that when production is increased, usages of energy also increase, and low production means usages of energy also decrease.

4.4. Correlation. The correlation coefficient is the measure of relations between two or more variables. This study uses the correlations method to determine the strength of a relationship and the strength between two variables we can easily calculate by correlation coefficient. We find out the correlation between total usages of energy with three different types of manufactured products.

In Figure 11, the top left histogram plot shows the total usages of energy, the bottom right histogram plot shows the total sheet weight, and the bottom left shows the merging of usages energy and total sheet weight. The correlation value of total usages of energy with total sheet weight is $0.29^{* * *}$. The star $\left({ }^{*}\right)$ values refer to the significant factor.

In Figure 12, the top left histogram plot shows the total usages of energy, the bottom right histogram plot shows the total Skelp weight, and the bottom left shows the merging of usages energy and total Skelp weight. The correlation value of total usages of energy with total Skelp weight is $0.49^{* * *}$. The star $\left(^{*}\right)$ values refer to the significant factor. 


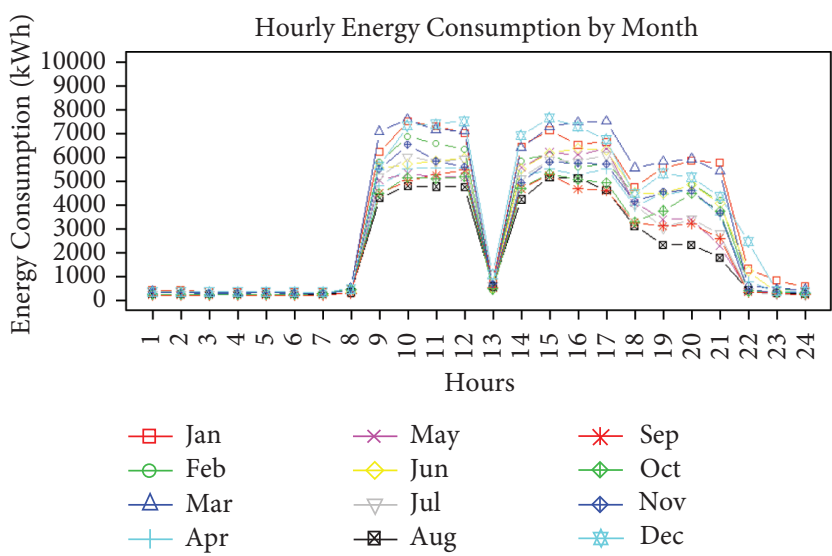

Figure 8: The diagram shows the per-month usage of energy for a steel factory in 2017.

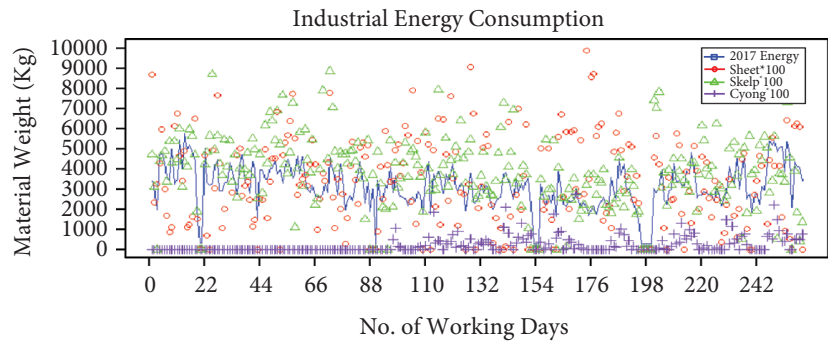

FIGURE 9: Different type's material weight of manufactured products with usages of energy for the number of working days in 2017.

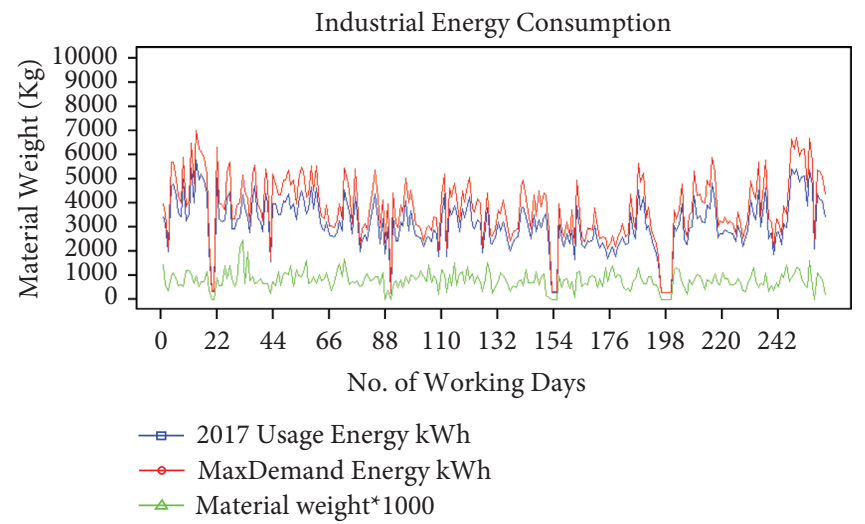

FIgURE 10: Total materials weight of manufactured products with the demand of energy and usages of energy for the number of working days in 2017.

In Figure 13, the top left histogram plot shows the total usages of energy. The bottom right histogram plot shows the total Cyong weight. The bottom left shows the merging of usages energy, and the bottom right shows the merging of total Cyong weight. The correlation value of total usages of energy with total Cyong weight is $0.27^{* *}$. The star $\left(^{*}\right)$ values refer to the significant factor.

4.5. Moving Average. Simple moving averages are the most fundamental type of moving average (SMA). The arithmetic average of a set of data is used to calculate it. A collection of numbers or prices is assembled in financial instruments and then split by the number of costs produced. In this study, we use weekly and monthly moving average methods based on total energy demand and total usages of energy.

Figure 14 shows the weekly and monthly moving average of total usage and energy demands for 2017. The red line shows the entire energy demands in the diagram. The green line depicts actual energy use, the purple line depicts the weekly moving average, and the blue line depicts the monthly moving average of total energy consumption in 2017. From the figure, we can see the October 2017 weekly moving average for usages of energy and energy demands is very low. December 2017 weekly moving average for usages of energy and energy demands is higher than any month. 


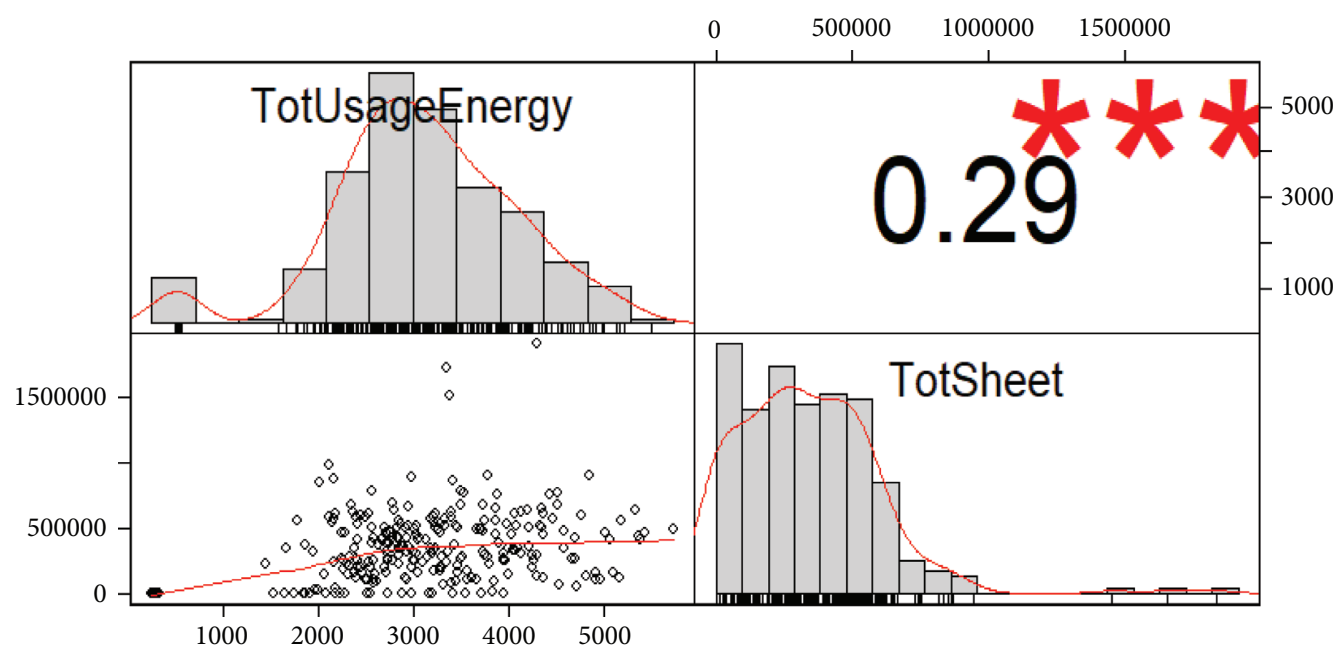

FIgURE 11: Diagram showing correlations values of total usages of energy and total sheet productions.

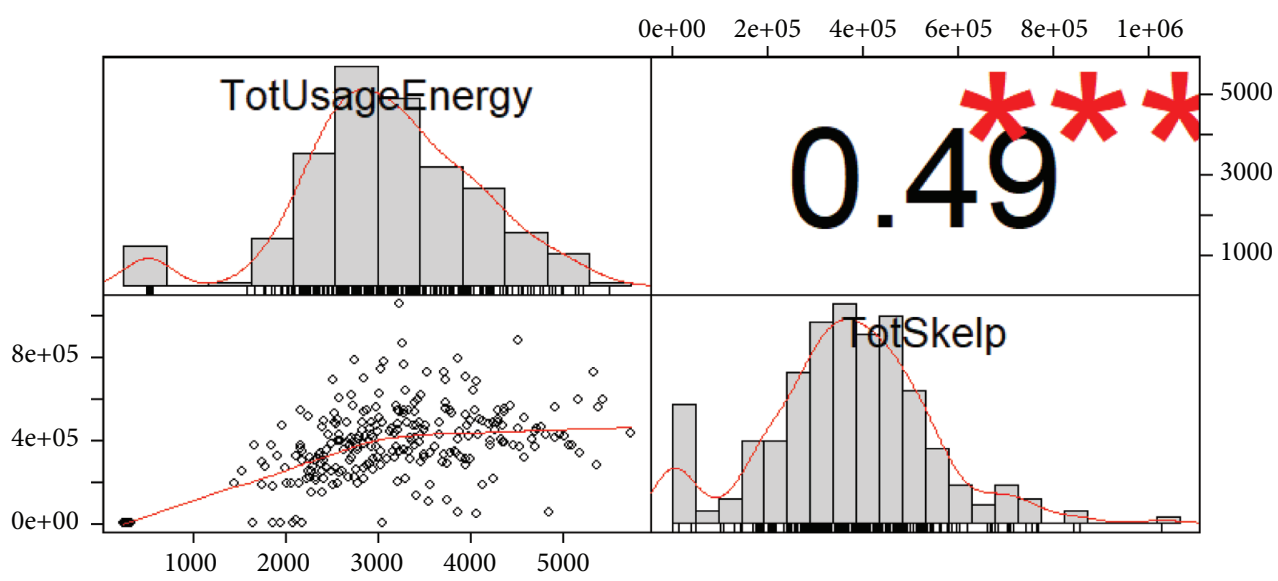

FIGURE 12: Diagram showing correlations values of total usages of energy and total Skelp productions.

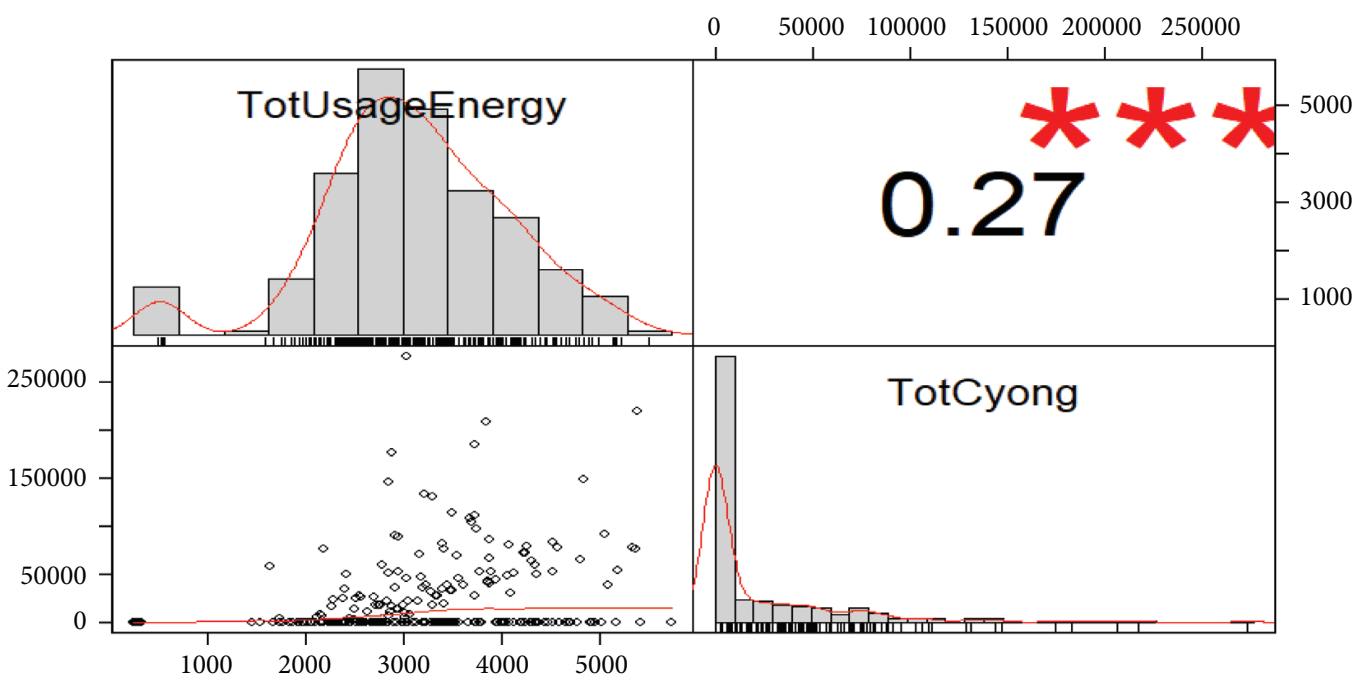

Figure 13: Diagram showing correlations values of total usages of energy and total Cyong productions. 


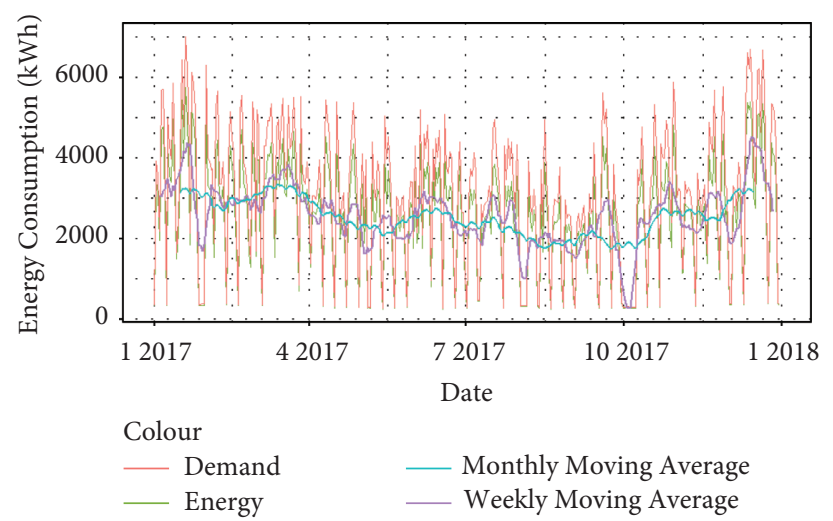

Figure 14: Diagram showing the weekly and monthly moving average of total usages and total demand of energy for the year 2017.

The figure shows that the weekly moving average is close to real data of total uses and energy demands.

4.6. ARIMA and SARIMA Forecasting. ARIMA and SARIMA are a set of well-defined data points that are recorded at regular intervals across time. ARIMA and SARIMA assist us in comprehending the underlying processes that contribute to a certain pattern in data points and forecast and monitor the data points.

Figure 15 shows decomposed usage of energy data in 2017. The first row is the actual usage of energy data and, based on this data, needs to extract seasonal trends and reminders, to identify the patterns, whether seasonal or not, and also check the line's slope (trend). Remainder values have been shown in the plot's last row after extracting seasonal and trend. In the plot, the $X$-axis shows months or time, and $Y$-axis shows actual data, extracted seasonal trend, extracted trend, and remainders. Finally, based on this plot, identified energy data have seasonal patterns and the slope of the line (trend).

Figure 16 shows forecasted energy data based on 2017 to predict the January month of 2018 using the ARIMA Model in the order of $(7,1$, and 4$)$. The $X$-axis represents the number of months in 2017, while the $Y$-axis represents the amount of energy consumed in kWh. Actual energy consumption is depicted in black, expected energy consumption is depicted in blue, and the maximum and minimum ranges of estimation prediction are depicted in grey. This plot is based on 2017 data to predict the January month of 2018 energy consumption.

Figure 17 shows forecasted energy data based on 2017 to predict the January month of 2018 by using the SARIMA Model in the order of $(7,1,4)(0,0,1)$ [30]. The $X$-axis shows the number of months in 2017, while the $Y$-axis shows the amount of energy used in kWh. The black line shows actual energy consumption, the blue line represents expected energy consumption, the grey line represents the maximum, and the grey line represents the lowest range of estimation prediction. This plot is based on 2017 data to predict the January month of 2018 energy consumption. The past and predicted data are more connected because both have more fluctuation (variations).
Figure 18 depicts a comparison between actual and anticipated energy usage statistics. The $X$-axis represents the number of days between January 1 and December 31, 2018, while the $y$-axis represents the quantity of energy consumed in $\mathrm{kWh}$. The data projected by the ARIMA model is shown by the blue line, while the pink line represents the actual energy usage. The green dotted line represents the highest and lowest ranges of 80 percent confidence intervals. The grey dotted line represents the top and bottom ranges of 95 percent confidence intervals. So, based on the predicted data, we suggest taking the upper range of 95 percent confident intervals and the lower range of 80 percent confident intervals.

Figure 19 depicts a comparison between original and predicted energy usage statistics. The $X$-axis represents the number of days between January 1 and January 31, 2018, while the $Y$-axis represents energy usage in $\mathrm{kWh}$. The blue line represents data that was forecasted using the SARIMA Model. The pink line shows real energy use, while the green dotted line shows the upper and lower ranges of 80 percent confidence intervals. The grey dotted line represents the top and lower range of 95 percent confidence intervals. As a result, we recommend using the top range of 95 percent confident intervals and the lower range of 80 percent confident intervals based on the forecasted data. From Table 2, we can easily find the performance of ARIMA and SARIMA forecasting models. Table 2 shows the forecasting model performance for the Daewoo Steel Factory for ARIMA and SARIMA. From the table, we can find the performance evaluation results for ARIMA by ME, RMSE, and MAE are $0.59,8.90$, and 6.72 . Performance evaluation results for SARIMA by ME, RMSE, and MAE are 0.24, 10.90, and 8.79.

The Daewoo steel plant produces a variety of energyrelated and manufacturing items under the names of Skelp, sheet, Cyong, and packaging. The variable importance for the Daewoo steel plant manufacturing items is depicted in Figure 20. We can see from the diagram that Skelp is the essential product for the Daewoo Steel Factory and that creating Skelp requires the most energy. Table 3 shows the using percentage of energy for each manufacturing product, and from the table, we find out that Skelp uses 49.82 percent of energy from total uses of energy. 


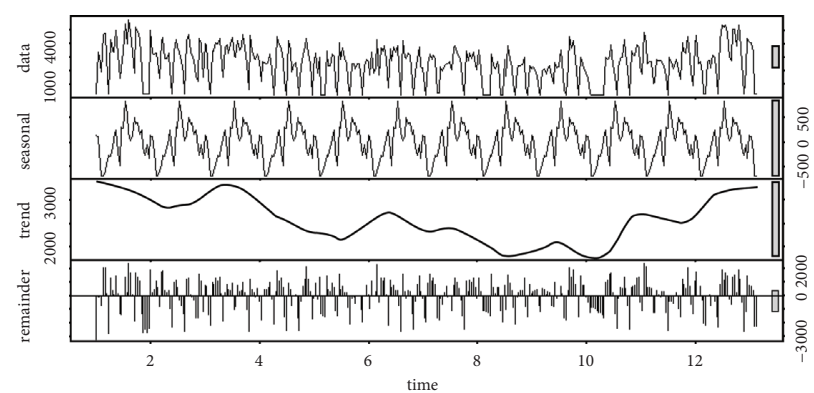

Figure 15: Diagram showing decomposed data in the year 2017.

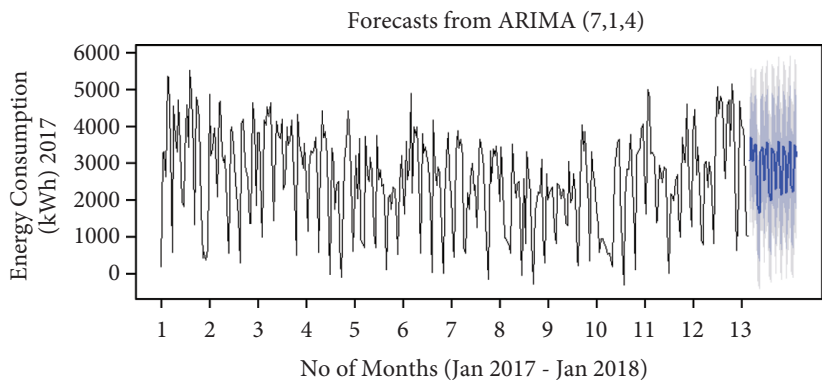

FIGURE 16: Diagram showing forecasting of energy consumption of January 2018 based on 2017 energy data by using ARIMA (7, 1, and 4) order.

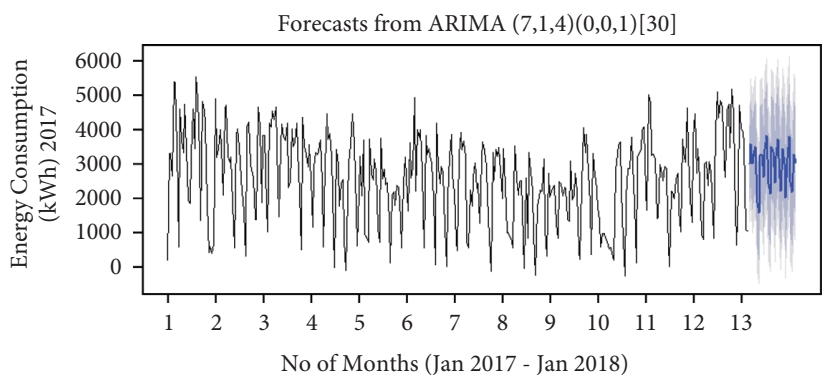

FIGURE 17: Diagram showing forecasting of energy consumption of January 2018 based on 2017 energy data by using seasonal ARIMA $(7,1,4)(0,0,0)$ order [30].

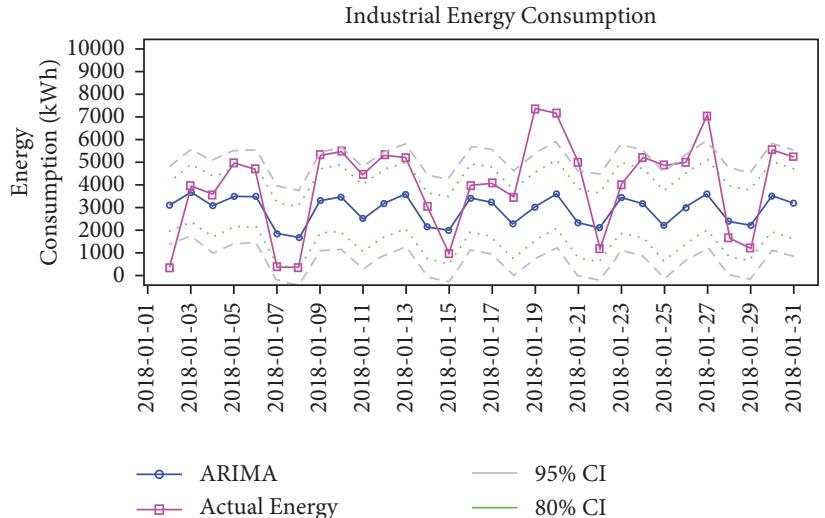

FIGURE 18: Diagram showing the comparison between actual energy data and ARIMA forecasted energy data of Jan 2018. 


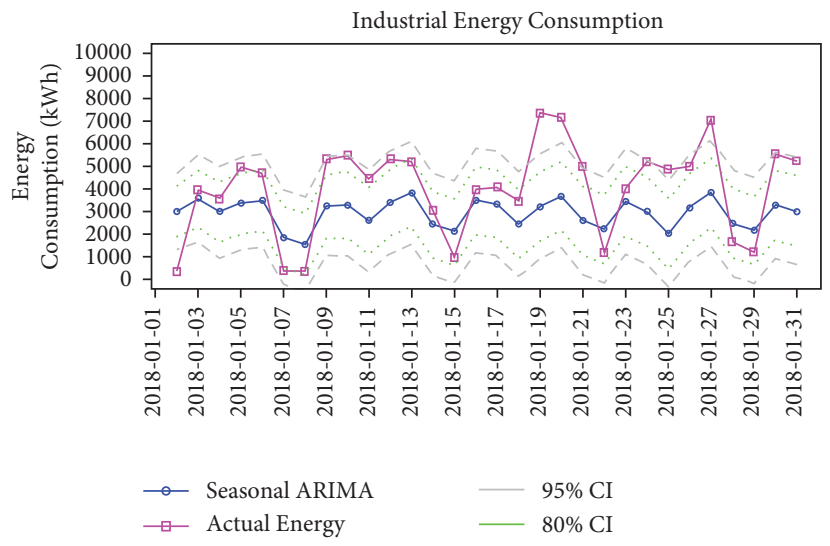

FIGURE 19: Diagram comparing actual energy data with seasonal ARIMA forecasted energy data of January for the year 2018.

TABLE 2: Forecasting model performance for Daewoo Steel Factory data set for ARIMA and SARIMA.

\begin{tabular}{lccc}
\hline Model & ME & RMSE & MAE \\
\hline ARIMA & .59 & 8.70 & 6.72 \\
SARIMA & .24 & 10.90 & 8.79 \\
\hline
\end{tabular}

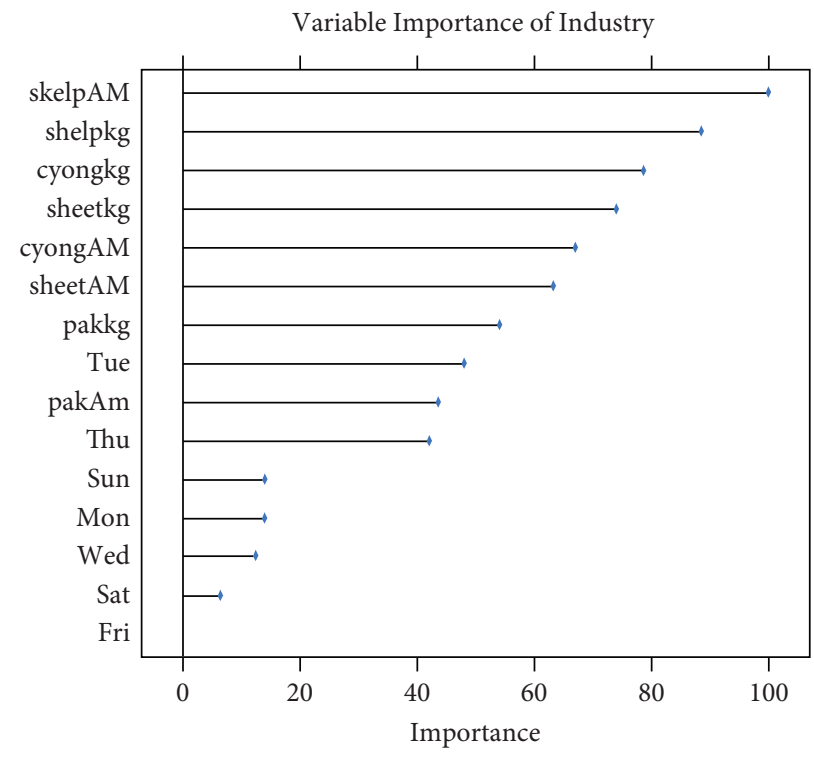

FIGURE 20: Variable importance for the Daewoo Steel Factory.

Table 3: Daewoo Steel Factory energy consumption table for the year 2017.

\begin{tabular}{lcc}
\hline Product name & Usages of energy $(\mathrm{kWh})$ & Using percentage \\
\hline Sheet & 322522.80 & 39.70 \\
Skelp & 404568.10 & 49.82 \\
Cyong & 45508.81 & 5.62 \\
Packaging & 34836.55 & 4.32 \\
Total & 807436.97 & 99.46 \\
\hline
\end{tabular}




\section{Discussion}

All results and analyses provided us an acuteness between usages of energy and the different material weight of manufactured products. Those results show us energy usage and energy demands with corresponding materials weight for manufactured products. The energy consumption pattern of the Daewoo steel industry is extraordinarily complicated, as illustrated in Figure 3, with practically continuous demand cycles followed by large spikes. Figure 4 shows energy consumption for 2017 in A, and B shows the first-week energy use for the Daewoo Steel Factory. In this study, we find the correlation value between usages of energy and three manufacturing products in Figures 11-13. From there, we find out Skelp has gotten higher correlations than the other two products. The correlations value is 49 between Skelp and usages of energy and a high significance factor $\left({ }^{* * *}\right)$. We can conclude that Skelp is the most important product for the Daewoo Steel Factory based on the correlation value. Figures 16 and 17 show the one-month forecasting curve for the Daewoo Steel Factory using the ARIMA and SARIMA time series models. We also find out the comparison curve among actual value and forecasting value from Figures 18 and 19. Table 2 shows the performance evaluation results for ARIMA by ME, RMSE, and MAE are $0.59,8.90$, and 6.72. Performance evaluation results for SARIMA by ME, RMSE, and MAE are 0.24, 10.90, and 8.79.

According to the variable importance functions in Figure 20, Skelp is the most important factor for energy utilization. Table 3 shows the percentage of energy for each manufacturing product, and from the table, we find out that Skelp uses 49.82 percent of energy from total uses of power. Table 1 shows that energy load prices are lower during offpeak hours than during mid-load and peak-load hours. As a consequence of the findings, we can observe that industrial energy consumption is relatively high in the summer and winter and that Skelp output is significantly associated with energy usage with a high significance factor. As a result, if factory officials decide to run two shifts in the factory, one during the day and one at night, as peak and off-peak hours, the plant's energy expenses will be reduced. Because Skelp production is closely connected with energy use, we can produce Skelp during the night shift.

\section{Conclusions}

We examined energy consumption and manufacturing data sets to determine how much energy is consumed and demanded based on the weights of the materials used in manufactured items. For 2017, we see the relationship curve between per-day energy usages and various types of materials weight for multiple types of manufacturing products and the relationship curve between per-day energy usages, demands for energy, and total materials weight for steel factory manufacturing products. In the steel plant, we can see the link between overall energy use and different types of material weight for making items. This study focuses on industrial energy usage analysis and forecasting to enhance energy utilization rates and make steel plants more profitable. This study shows the one-month forecasting curve for steel factories using the ARIMA and SARIMA time series models and finds the comparison curve between the actual and forecasting values. Table 3 shows that majority of energy is used for sheet production at 39.70 percent, Skelp production at 49.82 percent, and Cyong production at 5.62 percent. In the year 2017, this smart factory produced the most Skelp with the maximum amount of electricity. Power costs are determined using three different daily rates in Korea: off-peak, peak, and mid-peak. Different voltage levels are also available to customers, including low voltage (220 V and $380 \mathrm{~V}$ ) and three voltage levels ranging from $3.3 \mathrm{kV}$ to $345 \mathrm{kV}$. We can observe that there is a considerable pricing difference between peak, mid-peak, and off-peak hours. The energy rate is more significant during peak and mid-peak hours than during off-peak hours. So, in order to make energy a profitable item for the business, our idea is to run two shifts in the factory, one throughout the day and one throughout the night, or during peak and off-peak hours, respectively, to lower the firm's energy expenditures. As we have discovered, Skelp production is closely connected with energy use, so allowing authorities to manufacture Skelp during the night shift.

\section{Data Availability}

Two types of data sets are available from Daewoo Steel Factory, South Korea.

\section{Conflicts of Interest}

The authors declare that they have no conflicts of interest.

\section{Acknowledgments}

The GJ-RIP fund had also promoted this study. This paper was supported by (in part) Sunchon National University Research Fund in 2020 (Grant number: 2020-0206). The Korea Institute of Energy Technology Evaluation and Planning (KETEP) grant funded by the Korean government (MOTIE) (20202020900060) had sponsored this work. This work was assisted by the Korea Institute of Energy Technology Evaluation and Planning (KETEP) and the Ministry of Trade, Industry \& Energy (MOTIE) of the Republic of Korea (No. 20172010000730).

\section{References}

[1] L. Xiao, W. Shao, T. Liang, and C. Wang, "A combined model based on multiple seasonal patterns and modified firefly algorithm for electrical load forecasting," Applied Energy, vol. 167pp. 135-153, C, 2016.

[2] Y. Liu, H. Chen, and L. Zhang, "Energy consumption prediction and diagnosis of public buildings based on support vector machine learning: a case study in China," Journal of Cleaner Production, vol. 272, no. 1, 2020.

[3] Z.-X. Wang, Q. Li, and L.-L. Pei, "A seasonal GM(1,1) model for forecasting the electricity consumption of the primary economic sectors," Energy, vol. 154, pp. 522-534, 2018.

[4] S.-M. Lee, Mid-term Korea Energy Demand Outlook, Korea Energy Economics Institute, Ulsan, South Korea, 2014. 
[5] A. B. M. Salman Rahman, M. Lee, and J. Lim, "A prediction model for steel factory manufacturing product based on energy consumption using data mining technique," Journal of Science and Engineering Management, vol. 1, no. 2, pp. 9-16, 2020.

[6] T. Geng and Y. Du, "The business model of intelligent manufacturing with Internet of Things and machine learning," Enterprise Information Systems, pp. 1-19, 2020.

[7] P. Lin, M. Li, X. Kong, J. Chen, G. Q. Huang, and M. Wang, "Synchronisation for smart factory - towards IoT-enabled mechanisms," International Journal of Computer Integrated Manufacturing, vol. 31, no. 7, pp. 624-635, 2017.

[8] A. B. M. Salman Rahman, M. Lee, and V. Ragu, "Identification of high significance product items through the analysis of energy consumption in steel factory," Journal of Knowledge Information Technology and Systems(JKITS), vol. 14, no. 3, pp. 275-289, 2019.

[9] G. David, "Ockwell, Energy and economic growth: grounding our understanding in physical reality," Energy Policy, vol. 36, pp. 4600-4604, 2008.

[10] C. Bataille and N. Melton, "Energy efficiency and economic growth: a retrospective CGE analysis for Canada from 2002 to 2012," Energy Economics, vol. 64, pp. 118-130, 2017.

[11] S. Nasreen and S. Anwar, "Causal relationship between trade openness, economic growth and energy consumption: a panel data analysis of Asian countries," Energy Policy, vol. 69, pp. 82-91, 2014.

[12] R. A. B. M. Salman, L. Myeongbae, and L. Jonghyun, "A comparative study of energy big data analysis for product management in a smart factory," JOEUC, vol. 34, no. 22022, pp. 1-17.

[13] V. E. Sathishkumar, C. Shin, and Y. Cho, "Efficient energy consumption prediction model for a data analytic-enabled industry building in a smart city," Building Research \& Information, vol. 49, no. 1, pp. 127-143, 2020.

[14] I. Cvitić, D. Perakovic, and M. Periša, "Novel classification of IoT devices based on traffic flow features," Journal of Organizational and End User Computing, vol. 33, no. 6, p. 1 20, 2021.

[15] A. B. M. Salman Rahman, M. Lee, and J. Lim, "Systematic analysis of environmental issues on ecological smart bee farm by linear regression model," International Journal of Hospitality Information Technology, vol. 14, no. 1, pp. 63-70, 2021.

[16] Q. Xiao, M. Shan, and M. Gao, "Parameter optimization for nonlinear grey Bernoulli model on biomass energy consumption prediction," Applied Soft Computing Journal, vol. 95, p. 1 12, 2020.

[17] Y.-S. Lee and L.-I. Tong, "Forecasting energy consumption using a grey model improved by incorporating genetic programming," Energy Conversion and Management, vol. 52, no. 1, pp. 147-152, 2011.

[18] X. Ma and Z. Liu, "Application of a novel time-delayed polynomial grey model to predict the natural gas consumption in China," Journal of Computational and Applied Mathematics, vol. 324, p. 17 24, 2017.

[19] X. Ma, Z. Liu, and Y. Wang, "Application of a novel nonlinear multivariate grey Bernoulli model to predict the tourist income of China," Journal of Computational and Applied Mathematics, vol. 347, pp. 84-94, 2019.

[20] W. Wu, X. Ma, Bo Zeng, Y. Wang, and Ca Wei, "Forecasting short-term renewable energy consumption of China using a novel fractional nonlinear grey Bernoulli model," Renewable Energy, vol. 140, p. 70 78, 2019.
[21] J. Qi Wang, Yu Du, and J. Wang, "LSTM based long-term energy consumption prediction with periodicity," Energy, vol. 197, p. 1 12, 2020.

[22] J. Liu, Y. Chen, J. Zhan, and F. Shang, "An on-line energy management strategy based on trip condition prediction for commuter plug-in hybrid electric vehicles," IEEE Transactions on Vehicular Technology, vol. 67, no. 5, pp. 3767-3781, 2018.

[23] R. Liu and X. Hu, "Case study of construction cost estimation in China electric power industry based on BIM technology," International Journal of Grid and Distributed Computing, vol. 9, no. 10, pp. 173-186, 2016.

[24] A. B. M. Salman Rahman, M. Lee, and J. Lim, "Identifying best fit ecological smart bee farm based on environmental issues by linear regression model," Journal of Green Engineering, vol. 11, no. 2, pp. 1951-1963, 2021.

[25] F. Tao, Y. Wang, Y. Zuo, H. Yang, and M. Zhang, "Internet of Things in product life-cycle energy management," Journal of Industrial Information Integration, vol. 1, pp. 26-39, 2016.

[26] W. Cai, K.-h. Lai, C. Liu et al., "Promoting sustainability of manufacturing industry through the lean energy-saving and emission-reduction strategy," The Science of the Total Environment, vol. 665, pp. 23-32, 2019.

[27] H.-T. Pao, "Forecast of electricity consumption and economic growth in Taiwan by state space modeling," Energy, vol. 34, no. 11, pp. 1779-1791, 2009.

[28] M. Kumar, V. M. Shenbagaraman, R. N. Shaw, and A. Ghosh, "Predictive data analysis for energy management of a smart factory leading to sustainability," Lecture Notes in Electrical Engineering, vol. 661, pp. 765-773, 2021.

[29] A. B. M. Salman Rahman, M. Lee, and J. Park, "Identifying high significance input factors in strawberry production using linear model," International Journal of Innovative Technology and Exploring Engineering (IJITEE), vol. 9, pp. 1680-1684, 2019.

[30] S. A. Vander Wiel, "Monitoring processes that wander using integrated moving average models," Technometrics, vol. 38, no. 2, pp. 139-151, 2012.

[31] W. W. S. Wei, “Time series analysis," Oxford Handbooks Online, vol. 2, pp. 1-51, 2013.

[32] D. S. d. O. Santos Júnior, J. F. L. de Oliveira, S. Paulo, and G. de Mattos Neto, "AnintelligenthybridizationofARIMAwithmachinelearningmodelsfortimeseriesforecasting," Knowledge-Based Systems, vol. 175, pp. 72-86, 2019.

[33] M. Khashei, M. Bijari, and S. R. Hejazi, "Combining seasonal ARIMA models with computational intelligence techniques for time series forecasting," Soft Computing, vol. 16, no. 6, pp. 1091-1105, 2012.

[34] A. K. Dubey, A. Kumar, and VicenteGarcía-Díaz, "Study and analysis of SARIMA and LSTM in forecasting time series data," Sustainable Energy Technologies and Assessments, vol. $47,20121$.

[35] S. Xu, H. K. Chan, and T. Zhang, "Forecasting the demand of the aviation industry using hybrid time series SARIMA-SVR approach," Transportation Research Part E: Logistics and Transportation Review, vol. 122, pp. 169-180, 2019.

[36] L. Tierney, “The R statistical computing environment," Lectures Notes in Statistics, vol. 902, pp. 435-447, 2012.

[37] A. B. M. Salman Rahman, V. 이명배, M. Yongyun Cho, fnm Chang-Sun Shin, fnm Ragu Vasanth, and fnm 박장우, "An analysis study based on linear regression model for changes of fruit size over plum diseases," Journal of Knowledge Information Technology and Systems, vol. 13, no. 5, pp. 509519, 2018. 